\title{
Isolation and characterization of a new human breast cancer cell line, KPL-4, expressing the Erb B family receptors and interleukin- 6
}

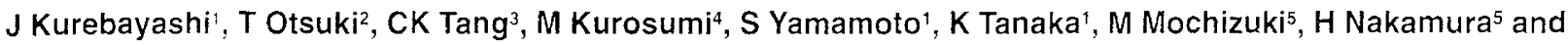 \\ H Sonoo
}

\begin{abstract}
Department of Breast and Thyroid Surgery and Department of Hygiene, Kawasaki Medical School, Kurashiki. Okayama 701-01. Japan; "Lombardi Cancer Center. Georgetown University Medicai Center, Washington DC 20007, USA: “Department of Pathology. Saitama Cancer Center, Kitaadachi-gun. Saitama 362 Japan: :Yokohama Research Center. Mitsubishi Chemical Corporation. Aoba-ku. Yokohama 227. Japan
\end{abstract}

\begin{abstract}
Summary A new human breast carcer cell line, KPL-4, was recently isolated from the malignant pleural effusion of a breast cancer patient with an inflammatory skin metastasis. This cell line can be cultured under serum-free conditions and is tumorigenic in female athymic nude mice. Flow cytometric analysis revealed the expression of Erb B-1, -2 and -3. Dot blot hybridization showed a 15-fold amplification of the erb B-2. Reverse transcription-polymerase chain reaction analysis showed a detectable level of mRNA expression of all the Erb B family receptors. In addition, all the receptors were autophosphorylated under a serum-supplemented condition. Unexpectedly, transplanted KPL-4 tumours induced cachexia of recipient mice. A high concentration of interleukin-6 (IL-6) was detected in both the culture medium and the serum of mice. The weight of tumours significantly correlated with the serum IL-6 level. The antiproliferative effect of a humanized anti-Erb B-2 monoclonal antibody, rhuMAbHER2, was investigated. This antibody significantly inhibited the growth of KPL-4 cells in vitro but modestly in vivo. Loss of mouse body weight was partly reversed by rhuMAbHER2. These findings suggest that KPL-4 cells may be useful in the development of new strategies against breast cancer overexpressing the Erb B family receptors and against IL-6-induced cachexia.
\end{abstract}

Keywords: breast cancer: cell line: Erb B-2; cachexia; interleukin-6

\begin{abstract}
Well-characterized human cancer cell lnes are essential reseatroh resources for studying cancer cell biology as well as lor stralegies igainst cancer cell growth and progression. We recently established a new human breast cancer cell line, designated KPL-t. from the malignant pleural cflusion of a breast cancer patient with an inlianmattery skin metastasis that was resistant to various chemendecrine therapies and radiation therapy. Inllammatory breas cancer, which is known to show an ageressive clinical hehaviour. has been reported to frequenty overexpress Erb B-2 or possess an amplified e-e't B-2 gente (Charpin et al, 1992: Prost et al. 1994). As cxpected, immunocytochemical. flow cytometric and reserse transcription polymerase chain reaction (RT-PCR) analyses showed an overexpression of Erb B-2 in this KPL-4 cell line. Dot blot hybridization also showed a 1.5 -fold amplification of the $(e-e, b)$ B-2 gene. In addition. Erb B-2 was autophosphorylated under a serum-supplemented condition. These findings suggest that this cell line has highly activated Erb B-2 and may be a usefut model for studying the roles of Erb B-2 receptor overexpression in breast cancer cells.

The Erb B family consists of four related proteins. All of these proteins are thought to be growth factor receptors. Recent reports halle suggested that these family members are activated by their
\end{abstract}

\section{Received 24 February 1998 \\ Revised 4 August 1998 \\ Accepted 5 August 1998}

Correspondence to: J Kurebayashi. Department of Breast and Thyroid Surgery. Kawasaki Medical School. 577 Matsushima, Kurashiki, Okayama 701-0192. Japan respective liginds, epidermal growlh factor (I:GF)/transtorming

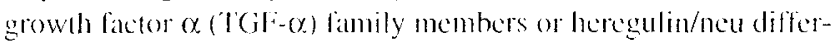
entiation factor members through heterodimer formation as well as homedimer formation (Carraway and Cantley. 1994: Earp et al. 1995). It has been suggested that the Both B-2 signal transduction pathway plays critical roles in growth regulation or the transformation of cells overexpressing multiple Frb B fimily members (Becrli el al, 1995: Kanmaganan ed al, 1996: Lewis et al, 1996: Zhang et al, 1996: (iraus-Porta ed al, 1997). In addition, either epidermal growth factor receptor (EGF-R) or Eith B-2 overexpression in breast cancer has been known to be a worse prognostic indicator (Sainsbury et al. 1987: Wright et al. 1989). A recent report also suggests that Erb B-3expression is frequently observed in breast tumours of a larger size and higher nuclear grade (Travis et al. 1996). These findings indicate that the Erb B family members and. in particular. Erb B-2 may play an important role in breast cancer cell growth and progression.

Immunohistochemical analysis of the Erb B-2 expression in breast cancer tissues has clearly demonstrated that Erb B-2 overexpression occurs only in breast cancer cells (Walker et al. 1989). Taken together with the importance of the Erb B-2 overexpression in breast cancer progression. breast cancer cell-specific overexpression of Erb B-2 indicates that blockade of the Erb B-2 signal transduction pathway may be a powerful and selective therapeutic method in patients with Erb B-2-overexpressing breast cancer (Shepard et al. 1991: Disis and Cheever. 1997). Recently: promising results from intravenous administration of a humanized anti-Erb B-2 monoclonal antibody to heavily-pretreated patients with Erb B-2-overexpressing recurrent breast cancer have been reported (Baselga et al. 1996). 
In this article. the isolation and characterization of our new KPL-4 human breast cancer cell line are presented. In addition. the antiproliferative effect of a humanized anti-Erb B-2 monoclonal antibods: thu.MAbHER2. which is under clinical study: on KPL-4 cells was studied both in vitro and in vivo. rhuMAbHER 2 significantly inhibited the growth of KPL-t cells under both anchoragedependent and -independent conditions. This antibody also modestly inhibited the growth of KPL-4 cells transplanted into female athymic nude mice. Unexpectedly: the transplanted tumours induced severe cachexia of the recipient mice. Interestingly, a high level of immunoreactive interleukin (IL) 6 was detected in both the culture medium and the serum of the recipient mice.

\section{MATERIALS AND METHODS}

\section{Patient and cell culture}

A 52-year-okd Japancese woman with a primary breast cancer underwent a modified radical mastectomy in September 1992. The histologic diagnosis of the revected specimen was invasive ductal carcinoma with muliple axillary lymph node metastases. Binclsemical analyses of estrogen receptor (IER), progesterone receptor (PeR) and le(il-R in the primary tumour showed that this temour expressed all the three receptors. In spite of adjuvant chemocodocrine therapy with a 5-fluorouracil derivative and

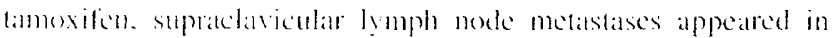
Nowember 1994. The patient received a combined therapy including chemoendocrine therapy with medroxyprogesterone acclate, cyclophosphamide. epirubicin and milomycin $C$ and radiation therapy from November 1994 10 December 1995. The recurrent discate progressed with little response to these therapies. Pleural cflusion and inflammatory skin metaskasis appeared in December 1995. Cytelogic examination of the effusion showed alypical epithelial cells. Mitoxintrone wats administered into the plenal effusion. Three wecks after the administation. the pleural alfusion increased and horacic drainage was performed to reduce the volume of the elfusion. During the same period the inflammat tory skin metastasis progeressed and the patient died of breast cancer in February 1996.

Malienant pleural eflusion was obtained from the pattent at the time of the thoracie drainage. A $50 \mathrm{ml}$ volume of the heparinized fluid was centrifteged at $150 \mathrm{~g}$ for $10 \mathrm{~min}$. The cell pellet wats resuspended and plated in T-25 flasks (Coming Japan, Tokyo, Japinl containing Dulbecos's modified tagkle's medium (DMI:M) supplemented with $10 \%$ letal bovine serum (FBS) (ICN Biochemincals, Costat Mesal. CA. USA). Serial patssages using $0.05 \%$ trypsin and 0.02\% EDTA in phosphate-buffered saline (PBS) were pertormed once or twiee a week. Since atypical epithelial cells predominamly grew in culture during all of the parsiges and cytogenetic analysis as described below strongly indicited the cells to be of a monoctonal origin. We have not attempled to subclone them.

\section{Morphologic analysis}

Hatenatoxylin-cosin taining of parafiin-embedded specimens to a performed using the conventional method in resected samples from nude mice bearing KPL-t transplanted tumours. Microphotographs were obtained with an Olympus $\mathrm{AH}-2$ microscope IOlympus. Tokyo. Japann. The cultured cells were observed and phase-contrast microphotographs were taken with an inverted Nikon Diaphot-TMD microscope (Nikon. Tokyo. Japan). For transmission electron microscopy. KPL-t transplanted tumours were resected. minced into blocks $1 \mathrm{~mm}$ in size and fixed with $2.5 \%$ glutaraldehyde in PBS for $2 \mathrm{~h}$ at $4^{\circ} \mathrm{C}$. After washing with PBS, the blocks were post-fixed with $1 \%$ osmium tetroxide in 0.1 il cacodylate buffer and embedded in epoxy resin. These blocks were cut into thin sections with a Supernova ultracutter (Reichert-Jung. Vienna. Austria) with a diamond knife. stained with uranyl acetate and lead citrate. and examined with a Hitachi H-7100 electron microscope (Hitachi Electronics. Tokyo. Japan). For immunocytochemical staining. paraffin sections of the tumour samples or cell pellets fixed with $5 \%$ buffered-formalin and embedded in paraffin werc dewaxed with xylenc. hydrated with PBS. treated with hydrogen peroxide for elimination of endogenous peroxidase and then processed by the immunoperoxidase procedure. Rabbit anti-cytokeratin (Milab. Tokyo, Japan). anticarcinoembryonic antigen (Milab). anti-CA 15-3 (Turner. Tokyo. Japan), anti-vimentin (Dako Japan. Tokyo, Japan) and anti-Erb B-2 (Triton Bioscience. Alameda. CA. USA) antibodies were used as the first antibody. Control experiments were performed by substituting nomal rabbit serum for the first antibody. The reaction was visualized by streptaridin-hiotin (Nichirei. Tokyo, Japan) techniques following the manufacturer's recommendations (Kurebayashi et al, 1995).

\section{Chromosomal analysis}

Cytogenetic analysis was performed adter this cell line had been passed 16 times. Semi-confluent cells were exposed to $0.1 \mu \mathrm{ml}$ ' colcemid for $4 \mathrm{~h}$ and detached with a trypsin solution. A hypotonic solution of $0.075 \mathrm{~m}$ potassium chloride was added. and the cells were fixed with $3: 1$ methatnol-acelic acid and statned conventionally with Giemsit.

\section{Receptor analysis}

ER and PgR in the cell pellet and tramsplanted tumours were measured by an encyme immunoassay using the ER-EIA and PgR-EIA kits (Dinabot. Tokyo, Japan) following the manulaceturer's recommendations. EGF-R in membranc fractions of the

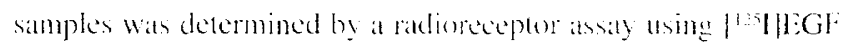
(New England Nuclear. Boston. MA. USA) as the ligand as described elsewhere (Yasui ce al. 1988).

\section{erb B-2 amplification}

Total cellular DNA was extracted by a conventional phenolchloroform method. DNA dot blot hybridization was performed as described previously (Kurebayashi et al. 1995). In brief. DNA samples were spotted onto Hybond $\mathrm{N}$ nylon sheets (Amersham. Arlington Heights. IL. LS.A) Which were hybridized with a :Plabelled specific DNA probe and exposed to X-ray films. Hybridization signals were analysed with a BSA200(0) biomaging analy ser (Fuji Fim. Tokyo. Japan). The degree of oncogene amplification was estimated by comparison with the radioactivity of placental DNA on the same membrane. The actin probe was used as an internal control. The DNA probe was a $1.6 \mathrm{~kb} E$ cor RI fragment of human c-erb B-2 obtained from Otsuka Phamaceutical Co. (Tokushima. Japan). 


\section{Flow cytometric analysis}

Approximately $1 \times 10^{k}$ cclls per sample were haricsted with try psin. stained with first antibodies for $1 \mathrm{~h}$ and washed with PBS wice. The samples were then stained with secondary fluorescein isothiocyanate (FITC)-antimouse antibody (Becton Dickinson. San Jose. CA. (SA) for $30 \mathrm{~min}$ and washed with PBS twice. The level of each Erb B receptor cell-1 was analysed by a flowcytometer (Becton Dickinson). The first antibodies were as follows: anti-EGF-R monoclonal antibody (Oncogene Science. Eniondale. NY. USA), anti-Ert B-2 monoclonal antibody (NeoMarker. Fremont. CA. USA). anti-Erb B-3 monoclonal antibody (Neo. Warker and anti-Frb B-t monoctonal antibody (Nem)arker).

\section{RT-PCR analysis}

Total cellular RNA was extracted with a TRI/ol RNA extraction kil (GIBCO BRL. Life Technologies. Gaithersbers. MD). (SSA) according to the manufacturer s recommendations. One microgram of lotal RNA and 120 pmol of Oligo (dT) primer in $1.3 \mu 1$ was heated 6) 70 ' C for 10 min lollowed by cooling on ice for 1 min. CDNA synthesis wals initialed with 200 mits of exverse tanscriptase (CLONTECH Labotateries Inc. Palo Alto. CA, ISA) under conditions recommended by the manufacturer. and the reation was allowed to proceed at $+2 \mathrm{C}$ for $1 \mathrm{~h}$. The reaction Wals terminated by heating at 9.4 C for 5 min. CDNA was finally dissolved in at total of 100$) \mu$ diethylprocartomate-treated water and frozen at zol c hefore use. Oligonucleotide primers for RT-PCR were designed using published secpuences of human

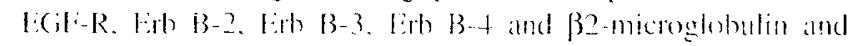
synthesized by the solid-phatse triester method (Table 1). PCR was performed using a $1: 50101: 100$ dilution of (DNA. 200 mov of each primer. 200 uM aNTPs. 10 min Tris-HCl (pH 8.3), 1.5 mu magnesium chloride. $50 \mathrm{~mm}$ potassium chloride, (0.01\% gelatin and 1 unit of Ampli-Tiq DNA polymeralse (Perkin-Elmer Cetus. Norwark. ("T. USA, ia a final volume of $20 \mu \mathrm{M}$. Alier an initial denaturation all 94 ( Cor 5 min, annealing at $57^{\circ} \mathrm{O}$ for $1 \mathrm{~min}$, and extension at 7.) ( for I min were performed on al DNA Thernal (yeder 2400) perkin-Elmer (etus). The linal extension was performed for 7 min. PC R products were andysed in a $1.2 \%$ agarose gel stained with elhidium bromide.

To compare relative expression kevels of each Erb B family receptor in human breast cancer cell lines, the PCR products in the agarose gel were stained with ethidium bromide. A gel image was obtained using the FAS-II LV-image analyser (TOYOBO. Tokyo. Japan 1. and the dencities of the products were quantified using the Quantity One version 2.5 (PDI Inc.. Huntington Station. NY. (SA). The relative expression levels were calculated as the density of the product of each Erb B family receptor divided by that of $\beta 2$-microglobulin from the same cell line. The following three human breast cancer cell lines were selected as the positive controls: the MDA-MB 231 cell line. highly expressing EGF-R: the SkBr-3 cell line. highly expressing Erh B-2 and Erb B-3 (Etheir ot al. 1996) and the T-47D cell line. highly expressing Erb B-i and Erb B-t (Plowman et al. 1993).

\section{Immunoprecipitation, Western blot and phosphorylation assay}

KPL-t or T-47D cells were cultured in 100 mm-dianneter dishes in DMEM supplemented with 5\% FBS, and then they were washed lwice with PBS and lysed in $1 \mathrm{ml}$ of lysis huffer ITris-buffered saline (pH 6.8) comlaining sodium dodecyl sulphate (SI)S) : and B-mercaptoethanoll. (ell lysates were precleared with $30 \mu \mathrm{t}$ of normal rabbit serum for $1 \mathrm{~h}$ at $f^{\circ} \mathrm{C}$. The lysates were then immunoprecipitated with cither anti-F(iF-R (O)nengenc Science), anti-Erh) B-2 ancibody (NeoMarker), anti-Erb B-3 (C-17. Samta Crus.

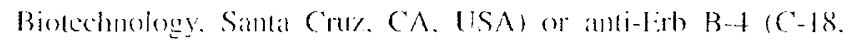
Simta (ru\% Biotchonology) antibody in combination with potein $A$ agarose (Pharmatcia, Piscataway. NJ, USA) orernight at $t^{\circ} \mathrm{C}$ with gente agitation. The immunoprecipitates were subsequenty washed four times in washing buffer prior to electrophoresis on a 4-16\% SDS polyacrylamicle gel electropheresis (SDS-PAGE) (Tris-glycine gradient ged) (Nover. San Diego. CA, USA). Next. they were electroblotted onto Hybond $\mathrm{ECL}$ nitrocellulose membrames (Amersham). After being blocked overnight with 5\% bovine serum althumin (BSA) in Tris-buffered saline containing $0.05 \%$ Tween 20 (pH 7.5), the blots were incuballed with monoclonal antiphosphotyrosine antibody (Lipstate Biotechnology Inc., lake Placid. NY. USA) for I h. After extensive washing they were then labelled with peroxidase-tagged sheep antimouse lga $(1: 100(0)$ for 30 min and visualized by ECL detection (Amersham) (Tang ctal. 1990).

To investigate the cross talk between EGF-R and Erb B-2.

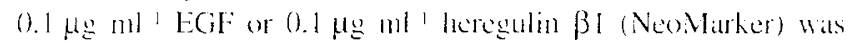
added 10 a routine culture medium $2+$ h before the cell harvest and then tyrosine phosphorylation of Erb B-2 was explored by the same method as described above.

Table 1 Sequence of oligonucleotide primers used in RT-PCR and size of predicted products amplified

\begin{tabular}{|c|c|c|}
\hline Primer (bp) & Sequence & Size of predicted product \\
\hline \multirow[t]{2}{*}{$E G F-R$} & Forward 5'-GCACGAGTAACAAGCTCACG-3' & 231 \\
\hline & Reverse 5'-TTCCTCTGATGATCTGCAGG-3' & \\
\hline \multirow[t]{2}{*}{ Erb B-2 } & Forward 5'-AGCAGAGGATGGAACACAGC-3' & 121 \\
\hline & Reverse 5'-CTCCTGGATATTGGCACTGG-3' & \\
\hline \multirow[t]{2}{*}{ Erb B-3 } & Forward 5'-TAGTGGTGAAGGACAATGGC-3' & 116 \\
\hline & Reverse 5'-AGGAGCACAGATGGTCTTGG-3' & \\
\hline \multirow[t]{2}{*}{ Erb B.4 } & Forward 5'-AGTCAGTGTGTGCAGGAACG-3' & 130 \\
\hline & Reverse 5'-TCAATGCTGGTTATCTCCAGG-3' & \\
\hline \multirow{3}{*}{$\beta 2$-microglobulin } & & \\
\hline & Fonward 5'CATCCAGCGTACTCCAAAGA-3' & 165 \\
\hline & Reverse 5'-GACAAGTCTGAATGCTCCAC-3' & \\
\hline
\end{tabular}




\section{Cell growth in vitro}

Two times $10^{5}$ cells per well were plated in 12-well plates (SB Medical. Tokyo. Japan) and grown in DMEM supplemented with $5 \%$ FBS at $37^{\circ} \mathrm{C}$ in a $5 \%$ carbon dioxide atmosphere. Triplicate wells were trypsinized every other day and the cell number was measured by a Coulter counter (Coulter Electronics. Harpenden. UK). The tumour doubling time was estimated from the linear portion of the grow th curve. To investigate the effect of EGF on the growth of KPL-t cells. $2 \times 10$ : cells per well were plated in the 12-well plates and grown in DMEM supplemented with 5\% FBS for 2 days. Then the cells were washed twice with PBS and grown in a serum-free DMEN supplemented with $0.1-10 \mu \mathrm{g}$ ml' EGF. The culture medium was changed every other day. Triplicate wells were trysinized 4 or 8 days after switching the culture medium and the cell number was counted.

The effect of a humanized anti-Erb B-2 monoclonal antibody. rhuMAbHER2 (provided by Mitsubishi Chemical Co.. Tokyo. Japan and designated MKC-54 in Japan) was investigated using this system. rhuMAbHER2 is a construct containing the antigen-binding loops of the murine fD.5 antibody with human variable region framework residues plus $\lg \mathrm{G}_{1}$ constant domains (Fendley et al. 1990): (arter et al. 1992). Two times $10^{5} \mathrm{KPL}-4$ cells per well were plated in the 12-well plates and grown in DMEM supplemented with $5 \%$ IBBS for 2 days. Then the cells were washed wice with PBS and

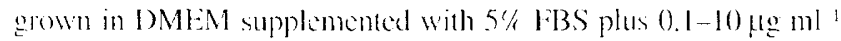
rhuMAbHER2 for 4 days. As the control, concentrations of human Ig(i, (Sigma Bioscience. St Louis. MO. USA) of the same amount were added to the medium. The medium was changed every other dily. Triplicate wells were trypsinized and the eell number was measured. To investigate the effect of shuMAbHER2 on the stimu-

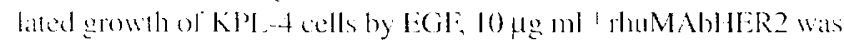
adked to DMEM supplemented with $0.1 \mu$ m $\mathrm{ml}$ ' EGF.

Anchorage-independent growh in soft agar was also investigated in this cell line. $\wedge$ top layer of $0.25 \%$ agarose (Iwaki Chemicals, Tokyo. Japan) in IDMLM containing KPL -4 cells at a density of $2 \times 10+$ per well was added to each well of a 6 -well plate (SB Medical) onto a bottom lityer of (0.5\% algatrose in DMEM containing (). $1 \ldots 10 \mu \mathrm{g}$ ml ' thuMAbHER2. $0.1 \mu \mathrm{g} \mathrm{ml}^{\prime}$ EGF alone or plus 10 $\mu 2 m$ ' rhuMAbHER2, or $10 \mu \mathrm{g} \mathrm{ml}^{1}{ }^{1}$ human IgG (ats a control). Afer 2-7 wecks colonies were stained with 250 pg per dish 3-(4.5dimethylthiazol-2-y)-2.5-diphenyl tetrazolium bromide (Sigma (hemicat (o.. Si I onis. MO. USA) and enumerated using an Ommicon 3600 Tumour Colony Image Analysis System (Imaging Products Internationall Inc.. Charlestown. VA. USA).

\section{Cell growth in vivo}

Approximately $1 \times 10 \mathrm{KPL}-4$ cells were inoculated into the mammany fat pad of tweek-old female nude mice or serere combined-immunodeficient (SCID) mice (CLEA Japan. Tokyo. Japan). Semi-confluen KPL-t cells were urypsinized and harvested and viable cells were couned in at haemocytometer using trypan blue exclusion. Tumour volume was calculated as the product of the latrest diameter. the orthogonal measurement and the tumour depth. Mean tumour volume was calculated as the sum of tumour volumes divided by the number of tumours. After the mice were sacrificed by cervical disocation. transplanted umours. lymph nodes. lungs. liver and kidness were collected. After measurement of the tumour weight the resected simples were fixed with $5 \%$ buffered-formalin and embedded in paraftin for morphologic analy sis.
To investigate the effect of rhuMAbHER? on the growth of KPL -4 cells transplanted into nude mice. approximately $5 \times 10^{\text {r }}$ KPL-t cells were injected into the right and left mammary fat pads of 4 -week-old female nude mice (two sites per mouse). In addition. to investigate the effect of rhuMAbHER? on the in vivo growth of KPL-1 human breast cancer cells that do not overexpress Erb B-2 (as the control cells). the cells were injected into 4-week-old female nude mice in the same manner. In the rhuMAbHER2-treated group. $20 \mathrm{mg} \mathrm{kg}^{-1}$ rhuMAbHER2 was intraperitoneally administered as a loading dose 2 weeks after the cell injections and then $10 \mathrm{mg} \mathrm{kg}$ ' rhuMAbHER2 was intraperitoneally administered once every week during 3-5 weeks after the cell injections. The same volumes of human $\mathrm{IgG}_{4}$ were administered in the control group in the same manner. Five mice (ten tumours) were treated in each group. Three-dimensional tumour size was measured with calipers every week after the cell injections. The body weight of the mice was measured every week before the administration of rhuMAbHER2. All the mice were sacrificed 5 weeks after the cell injections. Then. mouse blood was collected and the serum was stored at $-800^{\circ} \mathrm{C}$ before use Transplanted lumours. axillary lymph nodes and lungs were resected, and the weight of tumours was measured.

The animal protocols for these experiments were approved by the Animal Care and Use Committee of Katwasaki Medical School.

\section{Measurement of IL-6}

IL-6 concentrations in the cullured medium and mouse serum were measured with a chemiluminescent enzyme immunoassay kit (Fujirebio, Tokyo, Japan) according to (he manulacturer's recommendations. Briefly, a mouse anti-humann IL-6 monoclonal antibody (1H1 61-10) wats used ats the first antibody and a mouse anti-human Il-6 monoclonal antibody (Fujirebio) labelled with alkaline phosphatase (HH 61-2 fiat') was used ats the second one. Alter removing the unbound second antibody, 3-2 2 -spiroadmantane)-4-methoxy-t-( $3^{\prime \prime}$-phosphoryloxy)phenyl-1,2-dioxetane disodium sall was added. Chemiluminesecence was measured with a Lumipulse luminometer (fujirebio). As the standard, 20)$10(0)$ pe $\mathrm{ml}$ ' human recombinan $\mathrm{ll}$ - 6 was used. The minimal detectable concentration of $1 \mathrm{~L}_{-}-6$ was $0.2 \mathrm{pe} \mathrm{ml}$. The intrat-assaly coefficients of vartiation for the high, midelle and low simple levels were $2.8 \% .2 .2 \%$ and $3.8 \%$, respectively. The inter-assaly coefficients of variation for these sample kevel were $3.6 \%, 4.9 \%$ and $8.6 \%$ (Takemura el al, 1996).

\section{Statistical analysis}

All dita are expressed as the mean \pm SD. Analysis of variance (ANOVA) with Stat View computer sofw are (ATMS Co.. Tokyo. Japan) was used to compare differences in the cumour volume. tumour weight. mouse body 4 eight and IL-6 concentration between two different groups. Two-sided $P<0.05$ was considered is statistically significant. The comelation coefficients were calct lated by linear regression analysis $1 \mathrm{ith}$ the same software.

\section{RESULTS}

\section{Isolation and characterization of the KPL-4 cell line}

KPL-t cells were isolated from the malignant pleural effusion of is postmenopausal breast cancer patient with an inflammatory skin 
A

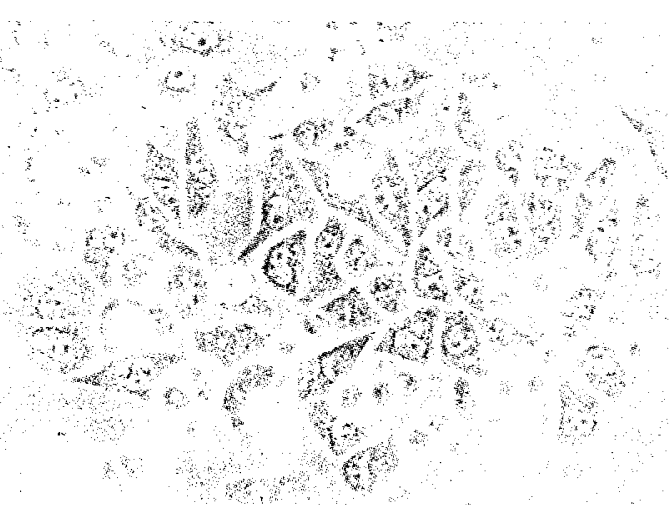

B

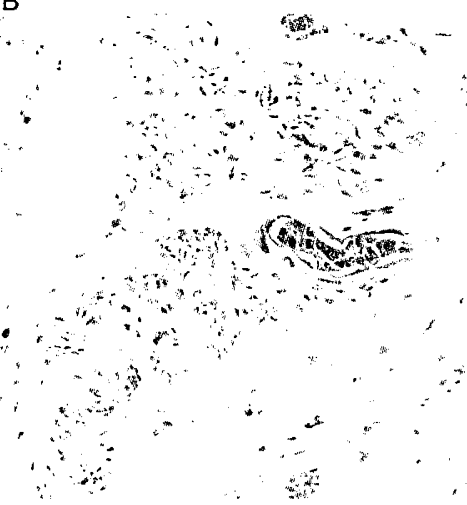

C

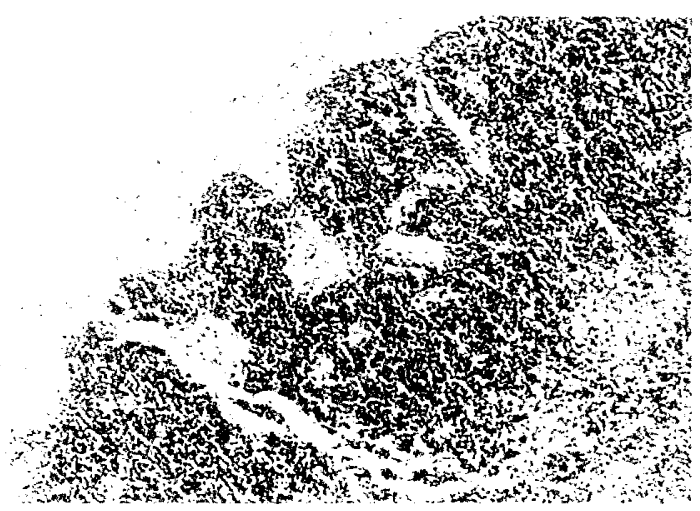

D

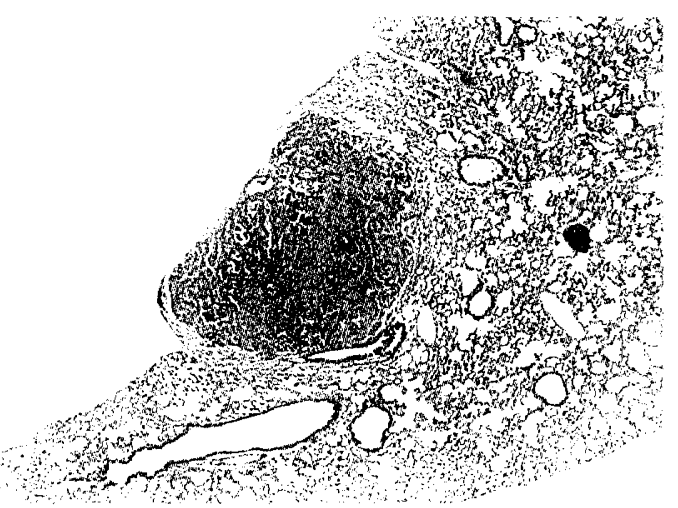

Figure 1 Microphotographs of KPL-4 cells in vitro and of KPL-4 transplanted tumours and their metastases in nude mice. (A) KPL-4 cells growing in a monolayer fashion (a phase-contrast photograph, original $\times 100)$. (B) The tumour occasionally showing vascular invasion into the surrounding stromal tissues (haematoxylin-eosin staining, original $\times 150$ ). (C) Tumour cells in the marginal sinus of an axillary lymph node (haematoxylin-eosin staining, original $x$. 75 ). (D) A metastasis in the lung (haematoxylin-eosin staining, original $\times 30$ )

melastasis which wats resistant to various herapies. Collected cells from the pation were cultured in DMISM supplemented with 5\% FBS through over 70 passiges for over a year. Although KPL-t cells basically grow in a monolayer fashion like cobblestones, they cond to pile up on cach other when they reach confluency. Each cell is polygonal and possesses a large nucleus with at single prominent nucleolus (Figure $1 \mathrm{~A}$ ). The population doubling time of this cell line in DMLM supplemented with $5 \% \mathrm{FBS}$ is approximately 30 h. Interestingly, KPL-4 cells grow slowly under serumfree conditions, and exogenous addition of EGF $\left(0.1-10 \mu \mathrm{g} m \mathrm{l}^{1}\right)$ dose-dependently stimulated their growth (Figure 2).

Karyotype analysis of the KPL-4 ecll line at the 16 th passage revealed the median chromosome number to be 5.3 with a range from 52 to $54(n=40)$. G-banding indicated marked chromosomal abnormalities (Figure 3). Sixteen common chromosomal aberrations were ohserved in all ten metaphases explored. Inmmunocytochemical analysis showed that KPL + cells express cytokeratin. carcinoembryonic antigen, CA 15-3 and Erb B-2, but not rimentin and ER. Biochemical analysis indicated the absence ol ER and PgR in this cell line. These findings were observed in both the culture cells and the transplanted tumours. Electron microscopic analysis revealed intracytoplasmic lumen and desmosome structures in the KPL-t cells transplanted into nude mice. These findings strongly suggest that this cell line is derived from a monoclonal human breast cancer cell.

To investigate the tumorigenicity of this cell line. approximately $1 \times 10^{-} \mathrm{KPL}-4$ cells ware injected into the mammary fat pad of female nude mice of SCID mice. KPL-4 cells developed lastgrowing tumours at a take rate of $100 \%$ in both nude mice and SCID mice $(n=10$ each $)$, and the growth curves of KPL-t transplanted tumours in these mice were identical (Figure t). The mice bearing KPL-t tumours became cakhexic 3 weets after the cell injections and $20 \%$ of them died within 5 weeks alter the cell injections in two separate experiments. Postmortem examination revealed that the transplanted tumours were oceasionally invasive 10 surrounding lissues (Figure 1B), such as skin and muscles, and a massive central necrosis of the tumours was frequently observed. No macroscopic metastasis was observed in the lymph nodes. lungs. liver or kidneys. However. microscopic examination of the resected specimens showed metastases into the lymph nodes (Figure IC) and lungs (Figure ID).

\section{Erb $\mathrm{B}$ family receptor expression in KPL-4 cells}

Immunocytochemical analysis of the KPL +4 cells revealed overexpress Erb B-2 oncoprotein. A radio-receptor assay showed that these cells possess approximately 50 fmol per mg protein of EGF$\mathrm{R}$ in the membrane fraction. Dot blot hybridization indicated an approximately 15-fold amplification of the erb B-2 gene in these cells (Figure $5 \mathrm{~A}$ ). These findings were observed in both the culture cells and the transplanted tumours. Flow cytometric analysis using monoclonal antibodies against Erb B family receptors demonstrated a high level of Erb B-2 and Erb B-3. a low level of EGF-R and no expression of Erb B-4 (Figure 5B). Howerer. an RT-PCR 


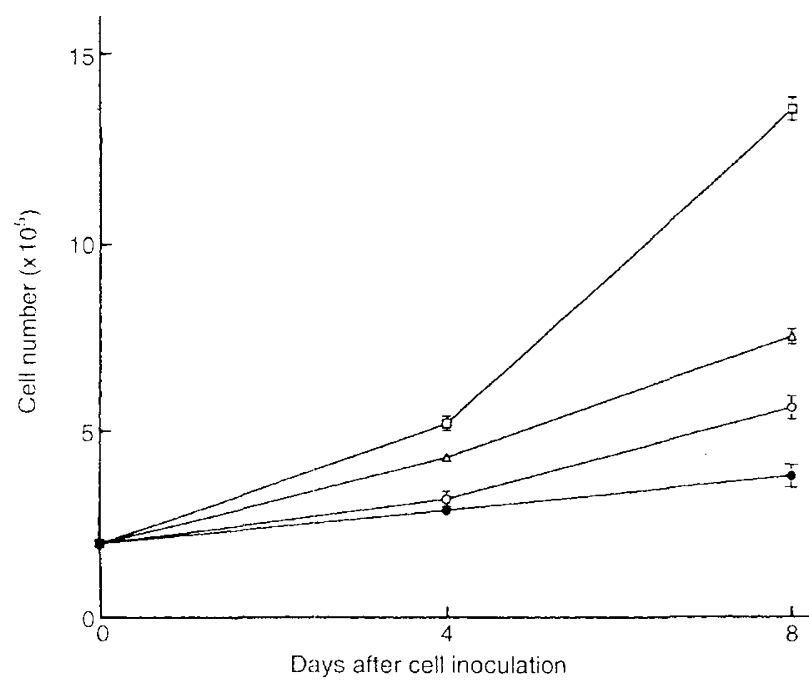

Figure 2 Anchorage-dependent growth of KPL-4 cells in a serum-free medium supplemented with EGF. KPL-4 cells were incubated with D-MEM with $0(0) .0 .1(), 1.0(\%)$ or $10(\cdots) \mu \mathrm{ml}^{-1} \mathrm{EGF}$ for 4 or 8 days. Bars show SD

analysis detected the mRNA of all the Erb $B$ family receptors in KPI.-t cells. The amoun of PCR products for Erb B-2 and Exh B 4 was higher that that for F(if-R and Erh B-3 (Figure 5C). To compare relative expression of each Lrb B family receplor, three human breast cancer cell lines were also analysed by the same $\mathrm{RT}$ PC R method. As shown in Table 2. the relative expression level of lith B-2 in KPl.-t cell line was highest in the explored cell lines. Immunoprecipitations were also performed usine specific anti-

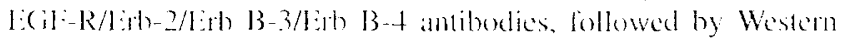
bloting antlysis with an anti-phosphotyrosine antibody. A stronge tyrosine phosphorylation of all four lish $B$ family receptors wats observed in KPl-t cells under a serum-supptemented condition but not in T-47D cells (Figure 5D). These findings suggest that KPL-4 cells possess all the Erb B family receptors activatable under a serum-supplemented condition.

\section{rhuMAbHER2 inhibits the growth of KPL-4 cells}

The addition of $0.1-10 \mu \mathrm{g} \mathrm{m} \mathrm{m}^{-1}$ rhuMAbHER2 to the medium supplemented with $5 \%$ FBS significantly inhibited the anchoragedependent growth of KPL-4 cells (Figure 6A). However. the same concentrations of rhuMAbHER 2 more clearly inhibited the anchorage-independent growth of KPL-4 cells in a serum-supplemented medium (Figure 6B). Furthermore, the addition of $10 \mu \mathrm{g} \mathrm{ml}{ }^{-1}$ rhuMAbHER2 to a serum-free medium supplemented with $0.1 \mu \mathrm{g} \mathrm{ml} \mathrm{I}^{-1}$ EGF significantly inhibited the stimulated growth of KPL-4 cells by EGF (Figure $6 \mathrm{C}$ ). More growh inhibition was observed under an anchorage-independent condition (Figure 6D).

To clarify the cross-talk between EGF-R and Erb B-2. tyrosine phosphorylation of Erb $B-2$ induced by EGF or heregulin was investigated. As expected in comparison with the control. Erb B-2 phosphorylation was enhanced by the exogenous addition of $0.1 \mu \mathrm{g} \mathrm{l}^{-1} \mathrm{EGF}$ into the medium (Figure 7 ).

To investigate the antiproliferative cllect of rumAhHER2 in vivo rhuMAbHER2 was administered intraperitoncally to mice bearing KPL-t tamsplanted tumours once every week for 4 weeks. The lumour volume 5 wecks alter the cell inoculations wats $826.6 \pm 295.3 \mathrm{~mm}:(n=10)$ in the rhuMAbHER2-treated group and $\left.105.7 \pm 542.9 \mathrm{~mm}^{\circ}(1)=10\right)$ in the control group (Figure $8 \mathrm{~A}$ ). The tumour weight was $0.67 \pm 0.17 \mathrm{~g}(n=10)$ in the rhuMAbHER?trated group and $0.91 \pm 0.30 \mathrm{~g}(n=10)$ in the control group. rhuMAbHER2 modestly inhibited the growth of KPI.-t-1ransplanted tumours $\left(P=0.256\right.$ for the tumour volume and $l^{\prime}=0.036$ for tumener weight). Becaltise nude nice bearing Kly $-t$ tumours becalme cachexic 3 wecks after the cell inoculations. mouse body weight was compatred between the two groups. The mousc body weight in the treated group (19.5 \pm 1.1 g) tended to be higher than

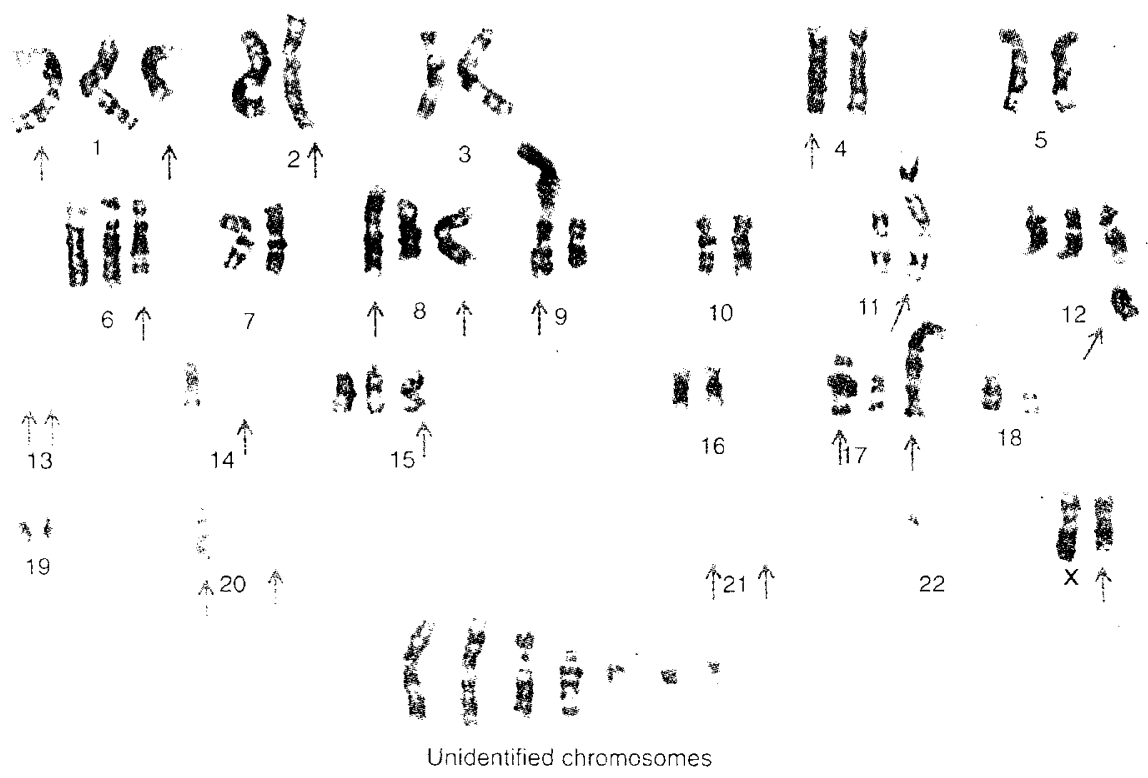

Figure 3 Karyotype analysis of KPL-4 cells displaying marked chromosomal abnormalities and unidentified marker chromosomes. Arrows indicate abnormal chromosomes 


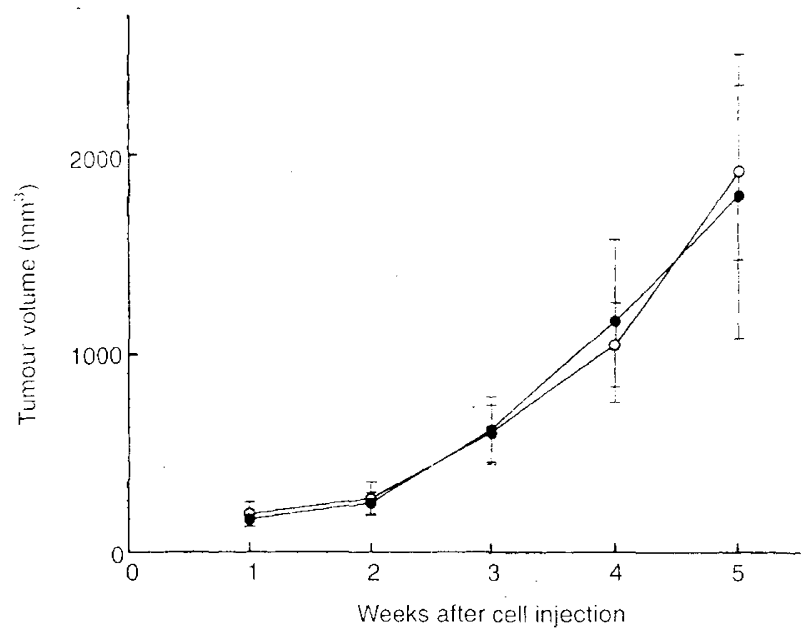

Figure 4 In vivo growth of KPL-4 cells transplanted into female athymic nude mice (-) or into femaie SCID mice ( ). One times $10^{-} \mathrm{KPL}-4$ cells were injected into the mammary fat pad of respective mice. Bars show SD that $(17.3 \pm 2.1 \mathrm{~g})$ in the control group + weeks after the cell inoculations $: P=0.086$. Figure $8 \mathrm{~B}$. Histologic examination of the resected tumours revealed no remarkable differences in tumour cell morphology or in lymphocyte infiltration between the two groups. The same tratment with rhu.MAbHER2 influenced neither the growth of KPL-1-transplanted tumours (data not shown) nor the mouse body weight (Figure 8B). The body weight of the mice bearing KPI-1 tumours was significantly higher than that of mice bearing KPL-t tumours $(P<0.0)$. Figure $8 \mathrm{~B}$ ).

\section{IL-6 levels in the culture medium and mouse serum}

The concentrations of IL- 6 in the culture medium and the mouse serum were measured with a chemiluminescent enzyme assay. The basal secretion of IL-6 from KPL-4 cells into DMEM supplemented with 5\% FBS was approximately 6.4 pe per $48 \mathrm{~h}$ per one million cells. The concentration of IL-6 in the culture medium of KPL-1 cells was below $0.2 \mathrm{P}$ ml ' Interestingly. a siginificant correlation was found between the concentrations of $11 .-6$ in the
A
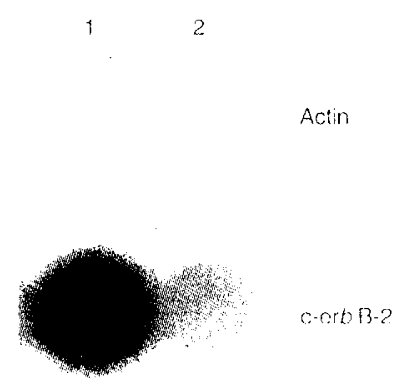

B
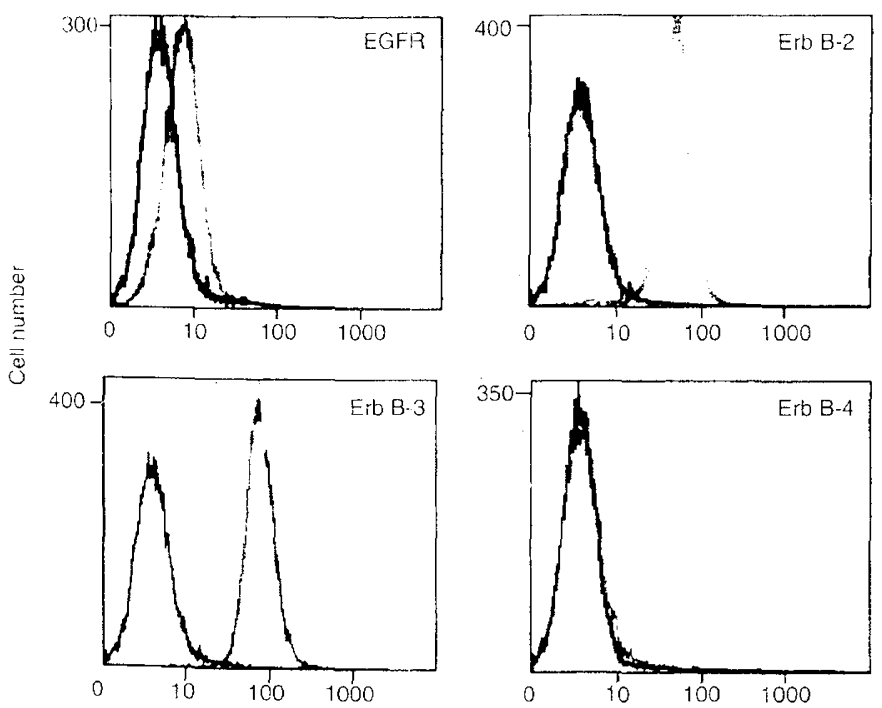

C

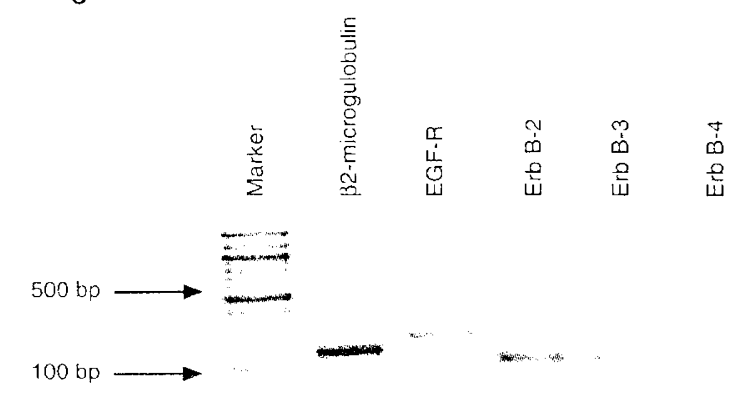

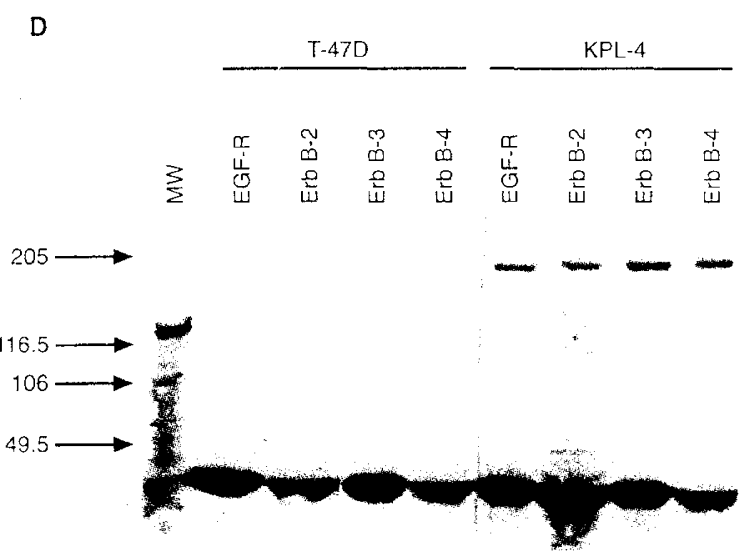

Figure 5 (A) DNA dot blot hybridization of the c-erb B-2 gene in KPL-4 cells: Lane 1. KPL-4 cells: Lane 2. human placental DNA. Actin was used as an internal control. (B) Flow cytometric analysis of the Erb B family receptors in KPL-4 cells. (-). incubated without a first antibody. (-), incubated with a first antibody against each Erb B family receptor. (C) RT-PCR analysis of the Erb B family receptors in KPL- 4 celis. The gel images are shown in inverted presentation. (D) Autophosphorylation of the Erb B family receptors in KPL-4 and T-47D cells. Cell lysate was subjected to immunoprecipitation with a specific antibody against each receptor. The prezipitates were then subjected to Western blotting with an antiphosphotyrosine antibody. Constitutive phosphorylation of ali the Erb B family receptors was observed only in KPL-4 cells. 
Table 2 Relative expression levels of Erb B family receptors in human breast cancer cell lines

\begin{tabular}{lcccc}
\hline & \multicolumn{4}{c}{ Relative expression } \\
\cline { 2 - 5 } Cell line & EGF-R & Erb B-2 & Erb B-3 & Erb B-4 \\
\hline KPL-4 & 0.56 & 0.83 & 0.39 & 0.51 \\
MDA-MB 231 & 0.65 & 0.52 & 0.13 & 0.18 \\
SkBr-3 & 0.28 & 0.78 & 0.59 & 0.75 \\
T-47D & 0.29 & 0.74 & 0.59 & 0.98 \\
\hline
\end{tabular}

:PCR-products in agarose gel were stained with ethidium bromide. a gel image was obtained using an image analyser. and the densities of the products were quantified by a computer-assisted method. The relative expression levels were calculated as the density of the product of each Erb B family receptor divided by that of 32 -microglobulin from the same cell line. Each value represents the mean of more than two separate experiments.

mouse sera and the KPL-t tumour weights ( $/$ f correlation coeffi(ient $=(0.831 . n=10 . P<0.6) 1)$ (Figure 9). In addition. the serum comentration of $1 \mathrm{~L}-6$ in the rhuMAbHER2-treated group $(38.2 \pm 9.3 p 9 m ! \cdot n=51$ was signilicantly lower than that in the control group $(67.0 \pm 26.1 . n=5)(P<0.05)$

\section{DISCUSSION}

Various human breast cancer cell bines hate been isolated worldwide and used in studies to understand breast cancer cell hiology

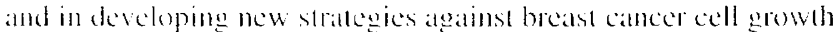

and progression. Two human breast cancer cell lines have already been isolated in our laboratory and their characterization has been reported elsewhere (Kurebayashi et al. 1995. 1996). In this paper the isolation and characterization of a third human breast cancer cell line. KPL-4. established in our laboratory are presented. This cell line was derived from a patient with a very aggressive inflammatory skin metastasis. As expected. KPL-t cells grew more rapidly than the other two cell lines both in vitro and in vivo. Our preliminary characterization revealed expression of all four Erb B family receptors in this cell line. In particular, both overexpression of Erb B-2 protein and $e r b$ B-2 gene amplification were observed in this cell line. Interestingly. KPL-4 cells can grow under a serumfree condition and also can grow rapidly in female athymic nude mice or SCID mice. There have been only two reports indicating that human breast cancer cel! lines overexpressing Erb B-2 can produce tumours in nude mice. In one of these reports. the $21 \mathrm{MT}$ cell line and its subclones produced transplanted tumours in nude mice after 2-1.3 weeks latency (Band et al. 1989). In the other report. the BT-474 cell line produced transplanted tumours in nude mice that received implants of slow release oestrogen pellets (Baselga el al, 1998). Therefore. to the best of our knowledge, this $\mathrm{KPI}-4$ cell line is the first human breast cancer edl line that overexpresses Erb B-2 and can produce rapid-growing tumours without oestrogen supplementation in vivo. In addition. it should be noted that transplanted K.PL-4 tumours induce severe cachexia in recipient mice and hegin to kill the mice only 4 weeks after cell inoculations. Postmortem histologic examination reveated metaslases from the transplanted tumours into lympln nodes and lungs
A

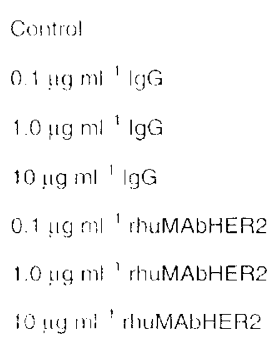

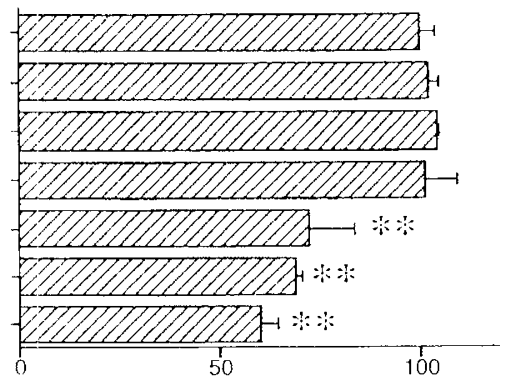

Cell number well ' (\% Control)
C
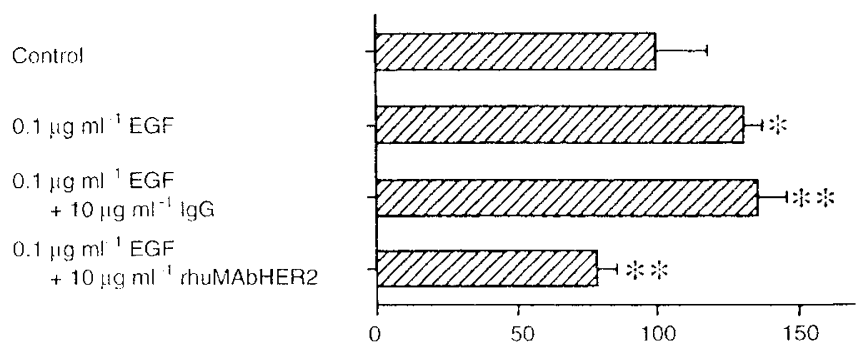

Cell number well ${ }^{1} \%$ Control)

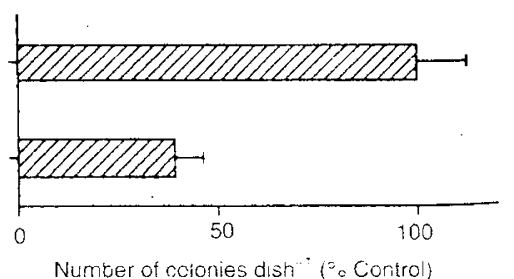

Figure 6 Antiproliferative effect of rhu:vLAbHER2 on KPL-4 ceils in vitro. (A) Anchorage-dependent growth in DMEM supplemented with $5^{\circ} \circ$ FBS: $0.1-$

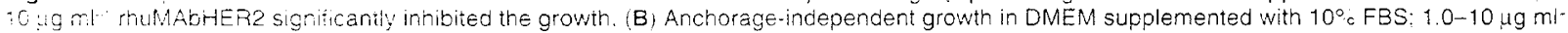
r.uMAbHER2 significantly inhibited the growth. (C) Anchorage-dependent growth under serum-free conditions. Although 0.1 ug ml- EGF significantiy

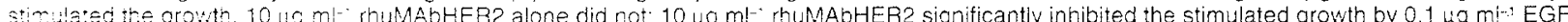

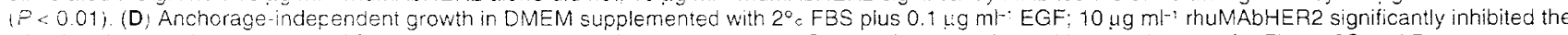
stimulated growth by $0.1 \mathrm{ig} \mathrm{m!} \cdot \mathrm{EGF}(P<0.01)$. Bars show SD. ${ }^{*} P<0.01$ : ${ }^{*} . P<0.05$ in comparison with control except for Figure $6 \mathrm{C}$ and $D$ 


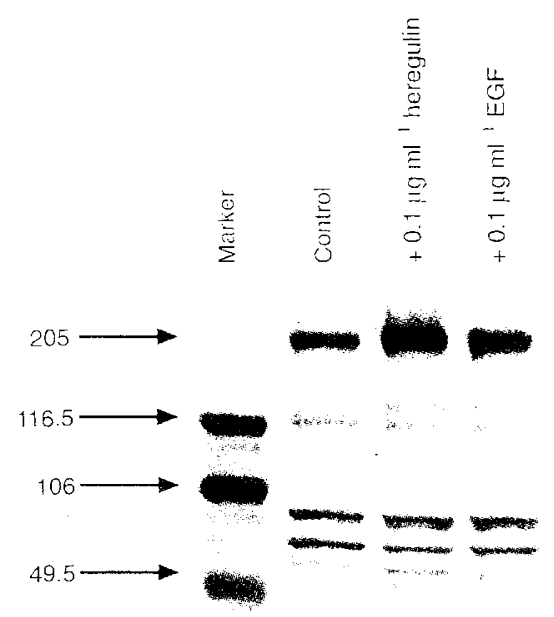

Figure 7 Tyrosine phosphorylation incluced by the exogenous addition of EGF $(0.1 \mu \mathrm{g} \mathrm{ml}$ ') and heregulin (31 $(0.1 \mu \mathrm{g} \mathrm{ml})$ to the culture medium. After 24-h tieatment, the cell lysate was subjected to immunoprecipitation with a specific antibody against Erb B-2. The precipitates were then subjected to Western blotting with an antiphosphotyrosine antibody. Tyrosine phosphorylation was enhanced by EGF as well as by heregulin $\beta 1$ in comparison with control.

(17gute 1). These lindings indicate that KPI.-4 eells possess a very ageressive phenotype like that of an inflammatory breast cancer. and that this cell line may be a useful model in studying the biology of such an ageressive breast cancer.

Although RT-PC R analysis showed derectable expression of all four Lith B family receptors (Figure $5($ ) and immunoprecipitation using specilic antibody against each brb B family receptor followed by Westem blot analysis with ambiphosphotyrosine antibody showed a remarkable autophosphorylation of each Ist B lamily receptor under at serum-stpplentented condition (lijgure 5). flow eytometric analysis of the expression of Erb B lamily receptors on the eell surface revealed no detectable expression of lin B-t (rïgure 5B). This discrepancy may be explained as follows. First. it may be possible that the antibody used in the immunmprecipitation wals more sensitive than the antibody used in the flow cytometric analysis. The former recognized the intracellular domain of Erb B-4 and the latter recognized its extracellular domain. It might be possible that the latter could not detect the low expression of Erb B-t in KPL-t cells. The second possibility is that Erb B-t may be internalized under a serum-supplemented condition and the antibody raised against the extracellular domain (1) Erb B-t could not detect Erb B-t expression in the flow cytometric analysis. Precise causes of this discre pancy remain to be clucidated. However, a remarkable autophophorylation of each Erb B family receptor strongly suggests that all of the Erb B family receptors are activated under a routine culture condition and that they may participate in the grow th of KPL..t cells. It is conceivable that some of the ligands for the Etb $\mathrm{B}$ family receptors may be produced by KPL- + cells and may induce autophosphory lation of the Erb B family receptors in an aulocrine or paracrine manner. In our preliminary experiment using a semi-quantitative RT-PCR. mRNA expression of the heregulin family members was undetectable in KPL-t cells (unpublished data). Further studies are needed to clarify this interesting hy pothesis.
A
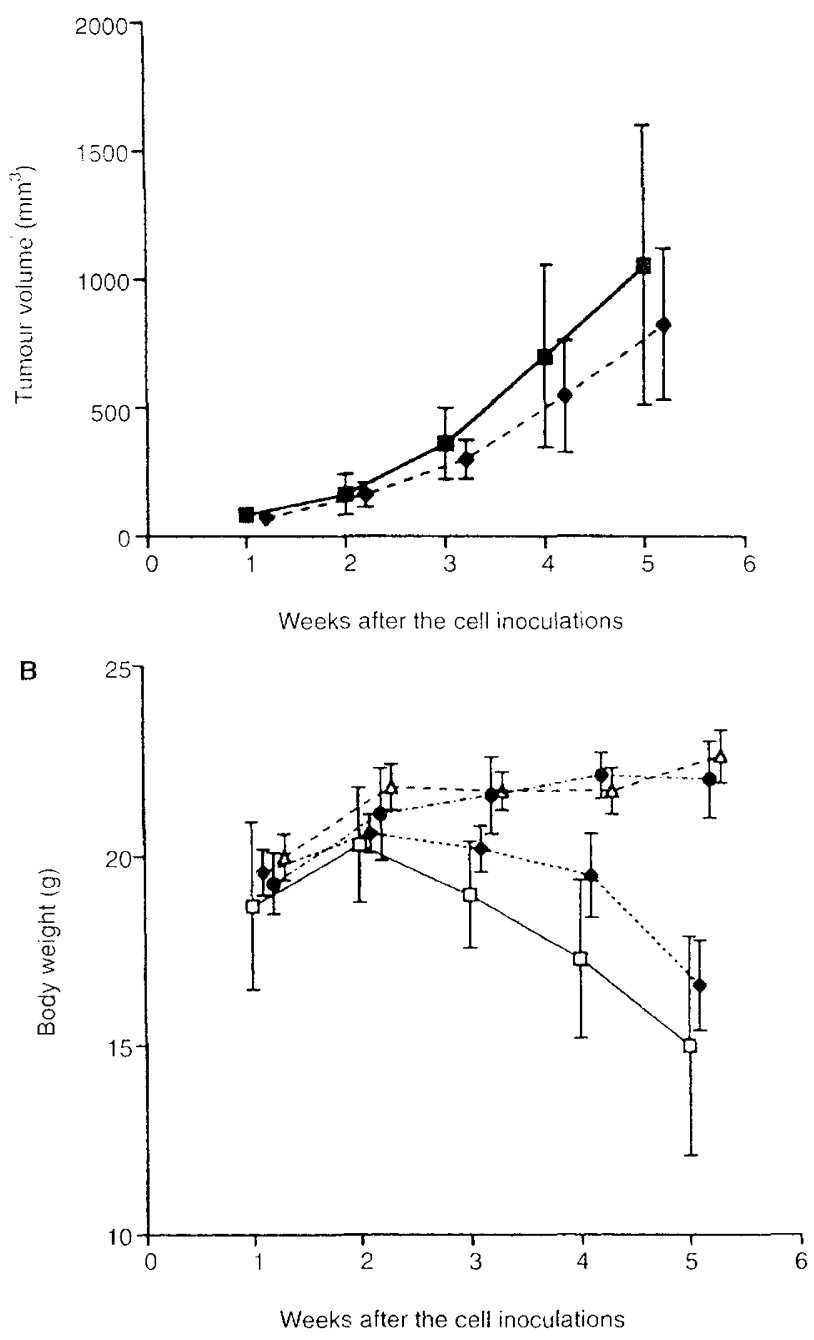

Figure 8 (A) Antiproliferative effect of rhuMAbHER2 on KPL-4-transplanted turnours in female athymic nude mice ( $n=10$ in each group). Five times $10^{6}$ $\mathrm{KPL}-4$ cells were injected into the mammary fat pad of nude mice.

rhUMAbHER2 was administered once a week from 2 weeks after the cell injections. control group; rhuMAbHER2-treated group. Bars show SD. (B) Changes in mouse body weight ( $n=5$ in each group). ...., control group (injected with KPL-1 cells): - rhuMAbHER2-treated group (injected with $\mathrm{KPL}-1$ cells); $\therefore$ control group (injected with $\mathrm{KPL}-4$ cells); rhuMAbHER2 treated group (injected with KPL-4 cells). Bars show SD

Our preliminary study indicated that cachexia in this nude mouse model may be induced by the secretion of IL. -6 from KPL- 4 cells. A high concentration of immunoreactive IL-6 was detected in the culture medium of KPL-t cells and in the serum of mice bearing KPL-t-transplanted tumours. In addition, the concentrations of IL-6 in the serum significantly correlated with the weight of KPL-1transplanted tumours (Figure 8). Very low levels of IL-6 were detected in the culture medium of KPL-1 cells (as a control) and the serum of mice bearing KPL-1 tumours (data not shown). A recent report suggest that oesophageal cancer patients with serum IL-6 levels equal to. or higher than, $7 \mathrm{pg} \mathrm{m} \mathrm{m}^{-1}$ are more cachexigenic than those with levels lower than $7 \mathrm{pg} \mathrm{m}{ }^{-1}$ (Oka et al. 1996). The serum levels of IL-6 in nude mice transplanted with KPL-4 cells were higher than $25 \mathrm{pg} \mathrm{ml-1}$ (Figure 8). Another recent report suggests that the serum IL-6 level of patients with metastatic breast cancer is 


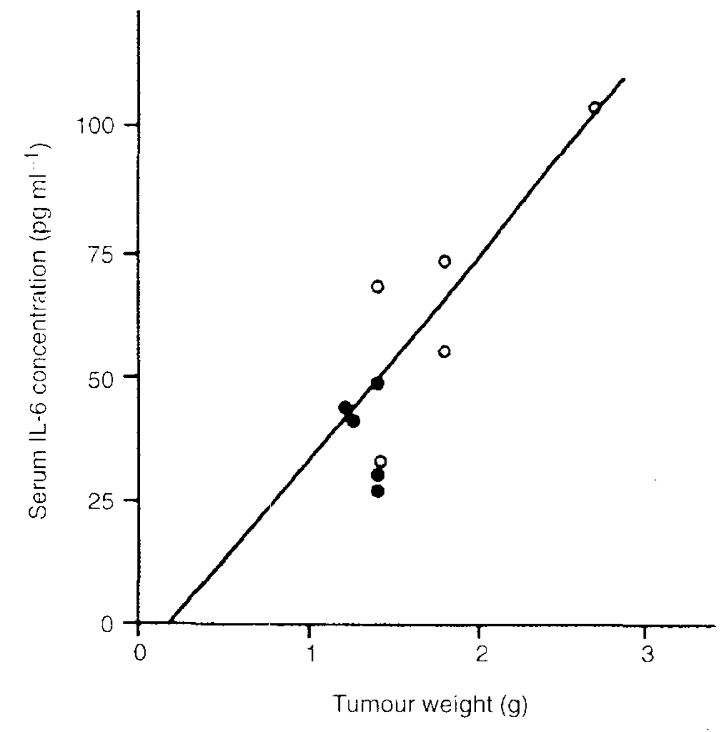

Figure 9 Relationship between the weight of KPL-4-transplanted tumours and the IL- 6 concentration ir the serum of recipient mice. IL- 6 concentrations were measured with a chemiluminescent enzyme immunoassay. Correlation coefficient $(n)=0.831(n=10 . P<0.01)$. , control group: . thuMAbHER2. treated group

significantly higher than that for nomal individuals and that the decrease in serum $11-6$ evels in those pationts significantly corre lates with their weight gain (Yambashita ed al. 1996). These findlines sugegest that overproduction and secretion of IL-6 from breast cancer cells is one of the main catuses of canner-indued cachexia in breast cancer. This hypothesis has been supported by experimental studies using a mouse colon calrimoma cell line. colon 26, and its subclones

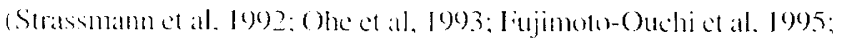
Yatsumoto et al. 1995). In our preliminary experiment. other possible cakclectic lactors, such as tumour necrosis factor- $\alpha$. leukatemia inhibitory factor. intericom- $\gamma$ and $11-1$ were not detectable in the serum of mice bearing KPL-t-transplanted tumours (unpublished datit). Further investigation is needed to charily whether IL-6 is the sole cause of catchexia in this model system.

A humanised momocknal antibody, whMAbHIR? Was examined in this sudy because it has recently been used in a clinical Phatse I trial in Japin. thuMABHER2 has already been evalualed in a Phase II clinical trial in the USA in patients with metastatic breast cancers that overexpress I:rb B-2 oncoprotein (Baselgat et al. 1996). As was expected. this antibody signiticantly inhibited the grow th of KPL -t cells is vitre and modestly in vivo. Because of the poor tumorigenicity of human breast cancer cell lines overexpressing Erb B-2. only one repert describing the anti-tumour effect of this antibed has been published so far (Baselgat et al. 1998). The antiproliferative effect of this antibody in vivo wats modest and the inhibition rate was approximately $30 \%$. However. it should be noted that this antiboly could inhibil the Erb B-2 signalling pathway in the transplanted tumours but could not induce antibody dependent cell-mediated cylolysis in this immunocompromised nude mouse model. Thus. this antibod could be expected to be more effective in women with normal immunity. Interestingly. the administration of this antibudy party reversed cachexia in recipient mice. The results of un preliminary experiment using this KPL-t ell line suggest that the. MA AbHER2 does not influence IL-6 secretion from KPL + cells in vitro (unpublished datit). Thus, it is likels that the antiproliferative effect of this antibody resulted in reduction of tumour volumes. in decrease of total IL-6 production from the tumours and in amelioration of mouse cachexia.

rhuMAbHER 2 significantly inhibited the stimulated growth of KPL +4 cells by EGF (Figure 6C. D). EGF dose-dependently stimulated the growth of KPL-4 cells under a serum-free condition (Figure 2). Furthermore. our preliminary study indicates that EGF stimulates the autophosphorylation of the Erb B-2 receptor in KPL- + cells (Figure 7). It has been suggested that EGF-R prefers heterodimerization with Erb B-2 to homodimerization with EGF. R (Wada et al. 1990: Quian et al. 1994: Earp et al. 1995). These findings suggest that EGF-stimulated heterodimerizaton between EGF-R and Erb B-2. and the subsequent transactivation of the Erb B-2 signalling pathway, may take part in the growth-promoting effect of EGF in this cell line. In other words, the blockade of the Erb B-2 signalling pathway may. at least in part. inhibit the EGFstimulated growth of breast cancer cells expressing both EGF-R and Erb B-2. The effect of rhuMAbHER2 on EGF-stimulated transactivation of the Erb B-2 protein is under investigation. Recently. some authors have observed that EGF can activate the helerodimer of Erb B-2 and Erb B-3 in the absence of EGF-R in murine IL-3-dependent 32D myeloid progenitor cells transfected with Erb B-2 and Erb B-3 and in MDA-MB 1.34 human breast carcinoma cells (Alimandi et al. 1997). Thus, it might be possible that rhuMAbHER2 inhibits Erb B-2 signal transduction through not only heterodimerization between EGF-R and Erb B-2 but also heterodinerization between Erb B-2 and Erb B-3. Further experiments are needed to elucidate the action mechanisms of the antiproliferative effect of rhuMAbHER2 on brealst cancer cells overexpressing multiple Erb B lamily receptors.

In conclusion, we have established a new human breast cancer cell line. KPI-4 from a recurrent breast cancer pattent. This cell line expresses all four members of the Eirh B family but, in particular. Eith B-2. KPl-4 cells can grow rapidly in culture and form tumours in female nude mice. Transplanted tumours cansed severe cachexia in mice and metastasized into the lymph nodes and lungs. A high level of immunoreactive IL-6 was detected in the culture medium and the serum of mice bearing KPL-t-transplanted tumours. A humbunized anti-lirh B-2 monoclonal antibody. thuMABHER2. inhibited the growh of KPL-4 cells both in vitro and in vivo. In addition. This antiboly significantly decreased serum It -6 levels of recipient mice and partly reversed mouse body weight loss. These findings indicate that this newly-established cell line, KPL-4. maty be a useful model hor studying the cell biology of aggressive breast cancers overexpressing the Erb $B$ family receptors and Il -6 and for investigating a novel therapentio strategy against them

\section{ACKNOWLEDGEMENTS}

This work wats supported in part by a grant from the Ministry of Education. Science. Sports and Culture of Japaln and by the research project grants (No. 8-301.9-106) from Kallasaki Nedical School. The authors would like to thank Dr Robent B Dickson. Lombardi Cancer Center. Georgetown University, for his helpful comments on this manuscript.

\section{REEFERENCES}

Alimandi M. Wing L-MY. Buturo D. Lee C-C. Kuo A. Franhel M. Fedi P. Ting C Lippman $M$ and Pieres JH (1997) Epidermal growth factor and betwellulin

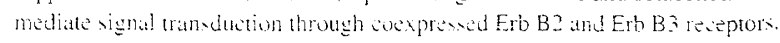
E.MBOJ 16: $5608-5617$ 


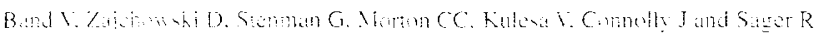

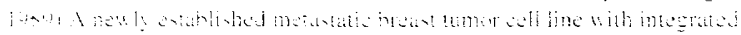

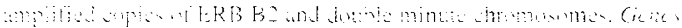

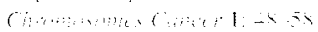

Bu- I T

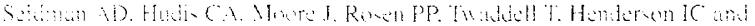

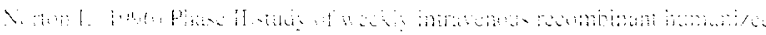

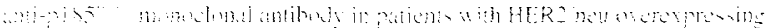

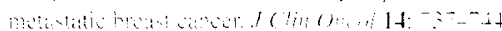

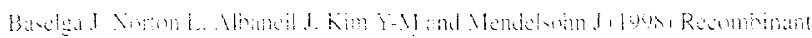

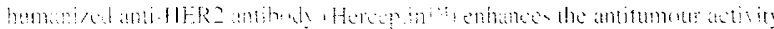

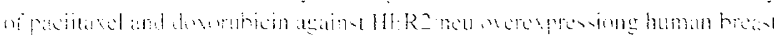

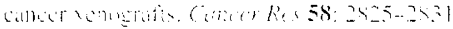

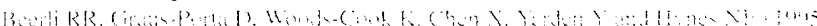

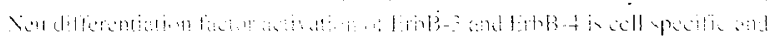

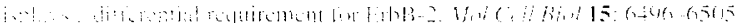

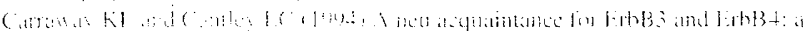

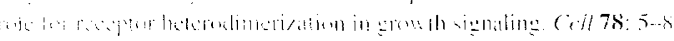

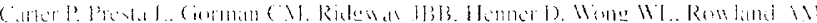

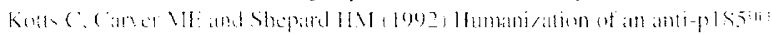

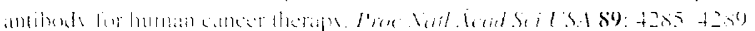

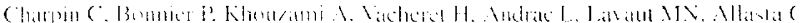

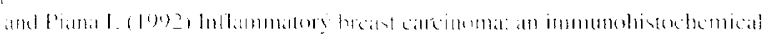

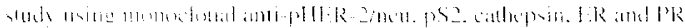

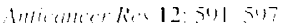

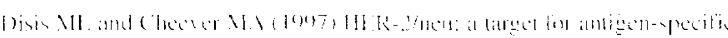

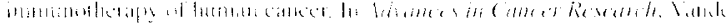

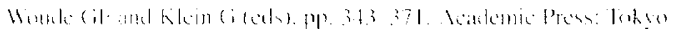

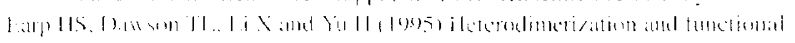

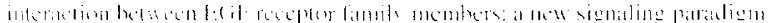

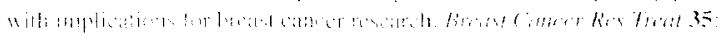
$11513 ?$

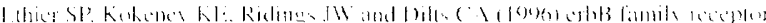

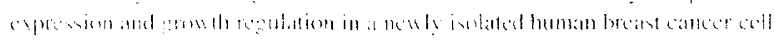

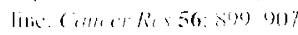

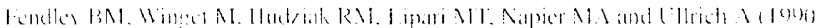

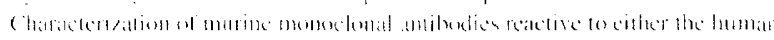

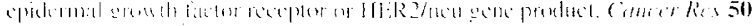
1501580

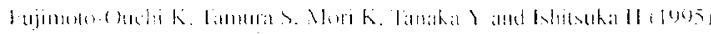

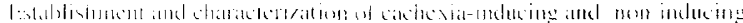

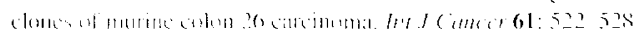

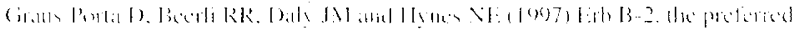

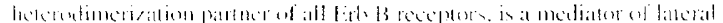

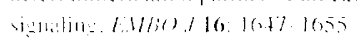

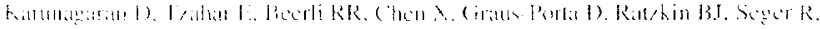

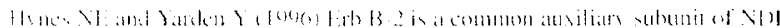

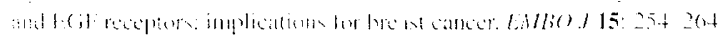

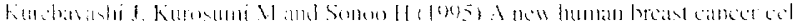
lan. K.t' I t

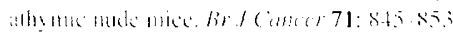

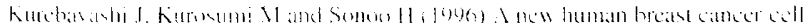

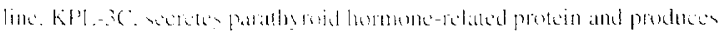

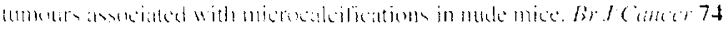
2(10). 207

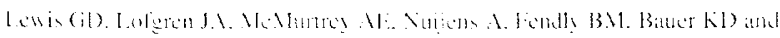

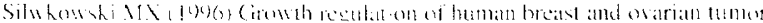

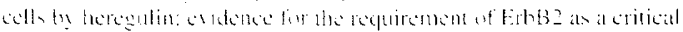

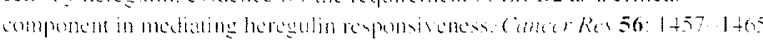

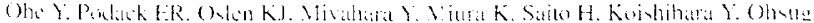

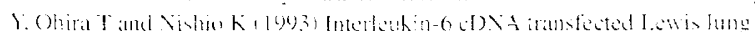

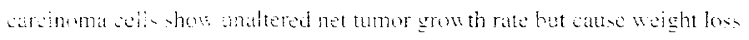

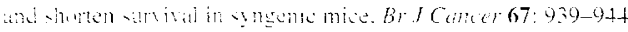

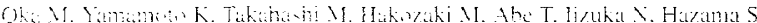

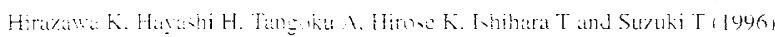

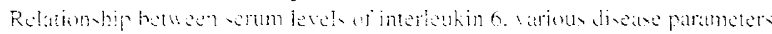

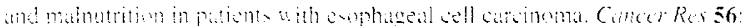
-

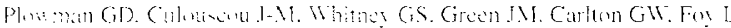

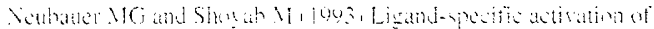

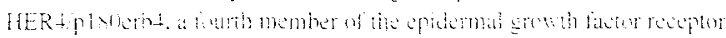

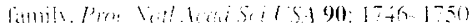

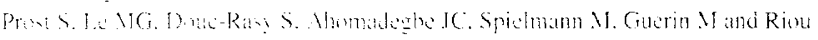

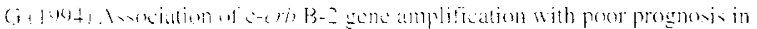

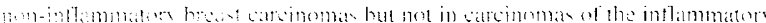

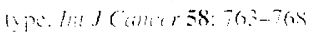

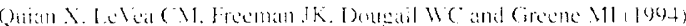

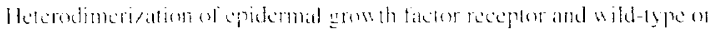

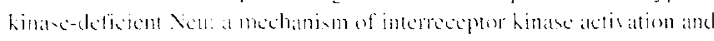

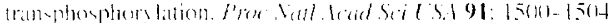

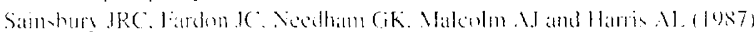

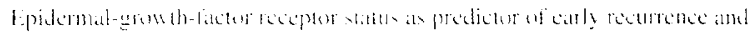

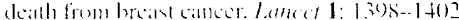

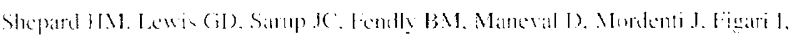

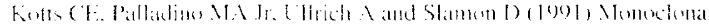

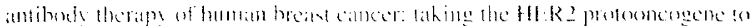

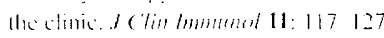

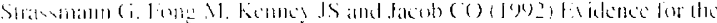

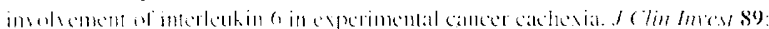
|xis| $\mid$ loit

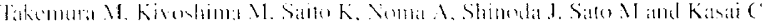

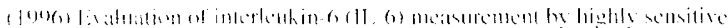

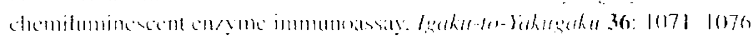

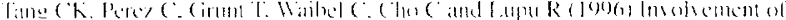

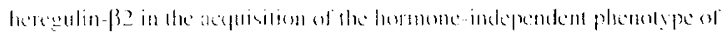

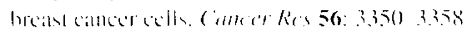

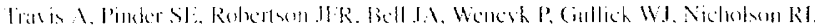

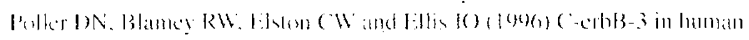

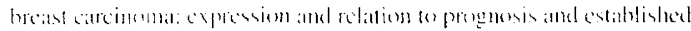

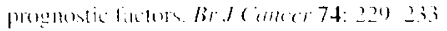

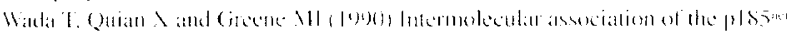

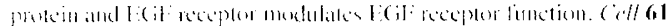

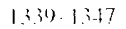

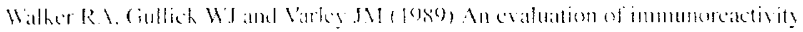

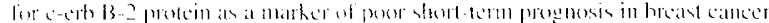

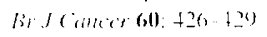

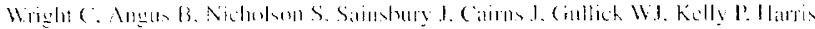

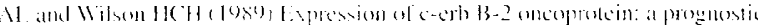

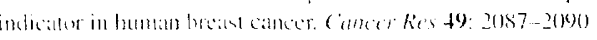

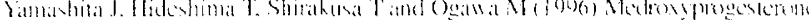

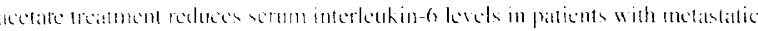

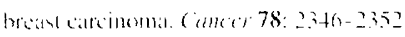

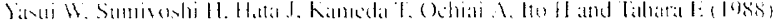

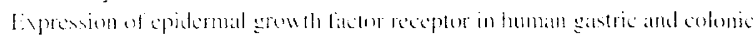

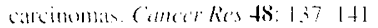

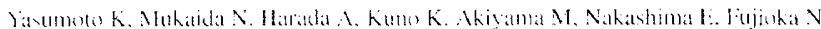

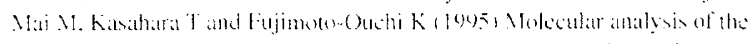

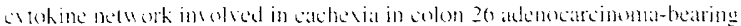

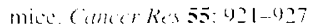

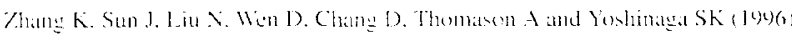

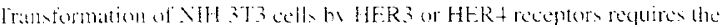

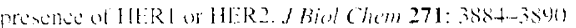

